Psychology of Language and Communication 2017, Vol. 21, No. 1

DE GRUYTER

OPEN

DOI: $10.1515 /$ plc-2017-0002

PATRICK DRUMM, DOROTHY W. JACKSON ${ }^{1}$

Ohio University Lancaster

\title{
GENERATING QUESTIONS: PROCESSING TIME CHANGES BETWEEN EARLY ADOLESCENCE AND YOUNG ADULTHOOD
}

\begin{abstract}
Information seeking by asking questions is fundamental to solving some problems. How quickly it proceeds can be important, especially if stakes are high. This experiment compared the processing times of three question types generated by early adolescents, middle adolescents, and young adults who sought to identify unknown target exemplars in a series of test arrays. Category questions, which eliminate alternatives based on their membership in contrasting mutually exclusive sets, were of two types: conceptual and perceptual. Conceptual category questions took longer to generate than perceptual category questions for all age groups. Syncretic questions, which refer to more than one category, took longer to generate than perceptual category questions for early adolescents, although they did not take longer to generate than perceptual category questions for the two older groups. Age-related changes in cognitive processing, syncretic thinking, and experience with hypothesis testing provide a framework for interpreting these results.
\end{abstract}

Key words: processing time, 20 questions, adolescence, problem solving, categorization

\section{Introduction}

Sometimes problem solvers must evaluate multiple alternative solutions, and by eliminating alternatives the best solution becomes apparent. Consider the identification problems facing the Observer Corps stationed along Britain's

\footnotetext{
1 Dorothy W. Jackson collaborated with the first author in designing and carrying out the study, and co-writing early drafts of this report. Unfortunately, she passed away before its completion. Timothy Drumm provided valuable assistance at the inception of the project. The authors also wish to thank the students, administrators, and faculty of the middle and senior high schools in northwestern Ohio for their part in this research.

Address for correspondence: Patrick Drumm, Division of Arts and Sciences, Ohio University Lancaster, 1570 Granville Pike, Lancaster, OH, 43112, USA. E-mail: drumm@ohio.edu
} 
coastline during the Battle of Britain and subsequent Blitz. Trained to recognize aircraft based on their shapes and tasked with discerning their types, particularly incoming German bombers, these volunteers, upon hearing the drone of engines in the skies above, needed to determine whether the planes were friends or foes (Victory, 1968). Quick identifications reported to their Sector Stations proved vital. To resolve their uncertainty, problem solvers in such situations typically generate questions and then attempt to answer them. "Is that a Junkers 88?" (i.e. a German Luftwaffe warplane) exemplifies a question needing an accurate answer during the Blitz. The question also performs a self-guiding function as the problem solver attempts to eliminate alternatives. After all, it might be a Bristol Blenheim (i.e. an R.A.F. warplane similar to the Junkers 88). Determining whether an aircraft belongs to a class of "German warplanes" eliminates competing alternatives. Ensuing decisions to act (i.e. report the sighting to the Sector Station) depend on how quickly the process produces an answer. Gibson (1947) acknowledged that aircraft identification as practiced by the Observer Corps relied on verbal analysis like that described above. Addressing this issue from a developmental perspective with broad theoretical implications, Vygotsky (1934/1986) and Luria (1976) argued that inner speech supports problem solving of this kind ${ }^{2}$.

Although the process described aboveseldomentails life or death consequences in modern human experience, selective pressure may have shaped it. During the MiddlePaleolithic ${ }^{3}$, those who quickly and correctly used that process to identify poisonous snakes in sudden close encounters or to recognize inedible plants while foraging for food probably survived those experiences in greater numbers than those who did not. Contemporary research has linked mortality in adults with individual differences in response times (Deary \& Der, 2005). If this questioning process is adaptive and modern humans rely on it, its development deserves scholarly attention. Given the duration of human maturation, both cognitive development and experience with eliminating alternatives should influence response times in such questions. Those assumptions underpin the present study.

\section{Questioning strategies}

When a self-generated question specifies one of several alternative solutions, affirmative or negative feedback can reduce the number of possible solutions (Mosher \& Hornsby, 1966; Slowiaczek, Klayman, Sherman, \& Skov, 1992). The process of seeking, gathering, organizing, and classifying information constitutes a mental workload that consumes time. In real-life situations, whether encountering a snake, experiencing a sudden loss of electrical power, or competing on a televised game show, how quickly someone seeks and organizes

2 Although sometimes problem solvers "think out loud," which is a form of private speech, inquiry is more often a mental event taking the form of an unspoken question posed prior to an empirical test.

3 Few would dispute that the Middle Paleolithic marked the emergence of cognitive and linguistic sophistication comparable to modern humans among our ancestors. That sophistication enabled inquiry-based problem solving. Of course, the possibility that such cognition appeared even earlier than this period is real. 
relevant information can be more than a trivial matter.

Framing questions depends in part on the ability to categorize information and therebyimposeorderonill-definedormultidimensionalstimuli. The fundamental step is the assignment of informational input to a class whose members are treated as equivalent (Mervis \& Rosch, 1981). In Europe and the Americas, the following exemplify common categories. Dogs, as a category, include Fox Terriers, Cocker Spaniels, and Great Danes. Aircraft include supersonic jets, combat drones, and prop-driven biplanes. Board games include chess, checkers and backgammon, and primary colors include red, yellow and blue. Categorization achieves an adaptive cognitive efficiency in which similar responses may be learned for each class member, and inferences may be drawn about novel entities that are plausible class members (Bruner, Goodnow, \& Austin, 1956; Hayes \& Taplin, 1993). Developmental changes in the ability to categorize correspond to changes in problem solving ability because categorization is crucial to efficient and successful questioning (Courage, 1989; Drumm \& Jackson, 1996; Eimas, 1970; Nelson \& Earl, 1973).

The ability to categorize follows a developmental progression from (a) focusing on instances to (b) inadequate partitioning of objects in the environment (i.e. Vygotsky's unorganized congeries) to (c) abstraction of discriminatory categories (Alexander \& Enns, 1988; Eimas, 1970; Luria, 1976; Vygotsky, 1934/1986). Young children often categorize in a haphazard fashion, but by middle childhood taxonomic categories provide them with useful organizational frameworks (Alexander \& Enns, 1988; Courage, 1989; Keil, 1989; Keil \& Kelly, 1987; Mandler \& Robinson, 1978; Markman, 1989).

A body of research on problem solving utilizes a task similar to the game of 20 Questions. In the task, participants ask questions answerable with yes or no to determine which picture in a set of pictures has been designated as the target. Participants attempt to eliminate one or more of the pictures with each question until they can specify the target. Well framed questions eliminate several pictures based on categorical contrasts. Such questions have been called multiple-item elimination questions (Alexander, Johnson, Leibham, \& DeBauge, 2004) and categorical questions (Courage, 1989), whereas the equivalent term constraining questions (Mosher \& Hornsby, 1966) aptly describes their ability to restrict the range or number of alternatives. In this report, the term category question refers to any question that rules out possible solutions based on membership in a specific category.

Studies using the 20 questions task indicate age-related improvement in questioning efficiency (Eimas, 1970; Drumm \& Jackson, 1996; Mosher \& Hornsby, 1966), which is a measure of progress toward a problem's solution. From middle childhood to young adulthood, problem solvers' questions generally eliminate more alternatives as age increases. Exceptions to this pattern include adults with intelligence deficits (Clément \& Gavornikova-Baligand, 2010) or with brain damage (Marshall, Karow, Morelli, Iden, \& Dixon, 2003; Upton \& 
Thompson, 1999). Training increases questioning efficiency (Denney, Jones, \& Krigel, 1979; Siegler, 1977). However, mere experience with the 20 questions task also helps. Both deaf and hearing children with experience playing the game produce equally efficient questions, but inexperienced hearing children outperform their inexperienced deaf peers in discovering efficient strategies, perhaps due to delayed language exposure among the deaf participants (Marschark \& Everhart, 1999). Taken together, these findings support the conclusion that levels of cognitive and linguistic development achieved by late adolescence/ young adulthood enable efficient questioning, at least as measured by the 20 questions approach. The theories advanced by Vygotsky (1934/1986) and Luria (1976) in which the social use of language fosters cognitive growth provide a framework for interpreting those results.

\section{Developmental changes in processing time}

A literature search revealed a dearth of research on developmental changes in the time required to generate verbal questions, although processing time has been studied in other areas of cognitive development. Findings in those areas suggest a pattern that may also occur in question generation, specifically that processing time predicts successful performance and that age accounts for much of the variance (Hale \& Jansen, 1994; Kail, 1996). For example, age correlates negatively with processing time and rate of speech (Kail, 1992; Kail \& Park, 1994). Hale (1990) found a linear relationship for age with tasks involving choice reaction, letter matching, mental rotation, and abstract matching in which 10-year-olds performed 1.8 times slower than young adults and 12-year-olds performed 1.5 times slower than young adults, but 15 -year-olds matched the young adults. Processing time appears to vary with the nature of the categories used. For example, response latencies associated with perceptual categories differ from those associated with conceptual categories (Sternberg, 1982). Importantly, both category types appeared in participant-generated questions focusing on either (a) the perceptual features of color, shape, and size, or (b) inferred relationships (via conceptual attributions) among a group of pictorial exemplars (Drumm \& Jackson, 1996; Jackson \& Jelinek, 1993). Sperber, Davies, Merrill, and McCauley (1982) also found age differences in processing times of perceptual versus non-perceptual categories, with the processing time of perceptual categories decreasing earlier (i.e. at a younger age) than non-perceptual categories. These, and other studies reviewed by Kail (1991), suggest that such changes are reliable developmental phenomena.

The present study uses a version of the 20-questions problem solving task initially described by Mosher \& Hornsby (1966) and modified by others (Drumm \& Jackson, 1996; Jackson \& Jelinek, 1993). It attempts to assess the effects of age and questioning strategy on the processing times (derived from response latencies) of participant-generated questions. The task reliably induces participants to organize information categorically as they generate questions 
to identify targets in multidimensional arrays based on the perceptual features and/or conceptual attributes in the arrays. The time taken to generate different question types could reflect a number of cognitive processing effects, including integration of thought with language (Luria, 1976; Vygotsky, 1934/1986), cognitive strain (Bruner, Goodnow \& Austin, 1956) or mental workload. This experiment varied perceptual features and conceptual attributes presented in arrays of exemplars and measured response latencies of different question types participants could ask. Either geometric figures or depictions of vehicles or animals serve as exemplars familiar to all participants and thus control for effects of domain-specific knowledge (Hambrick \& Engle, 2002). Because problem solvers encounter both dimensions in the real world, perceptual features determined the exemplars in one test array, conceptual attributes determined the exemplars in one test array, and a mixture of both determined the exemplars in one test array.

The predictions investigated in the present study derive from developmental processing time research. General agreement that processing time decreases with age across a variety of cognitive tasks (Fry \& Hale, 1996; Hale, 1990; Kail, 1991, 1993) leads to the prediction that processing time decreases with age in the 20-questions task. Because categorical thinking appears to demand more time when conceptual categories form the basis of responses (Edwards, 1969; Sperber, Davies, Merrill, \& McCauley, 1982; Sternberg, 1982), the prediction tested is that questions based on conceptual contrasts take longer to generate than questions based on visual features.

\section{Method}

\section{Participants}

Sixty early adolescent middle school students $(\bar{X}=13.5$ years, $S D=0.8)$, 60 middle adolescent high school students $(\bar{X}=16.8$ years, $S D=0.9)$, and 60 young adult college students $(\bar{X}=21.3$ years; $S D=1.8)$ formed three groups of participants with equal numbers of males and females. They met criteria of normal color vision and enrollment in regular classes in Midwestern North American schools.

\section{Procedure}

Arrays. Different types of categories were controlled and exhibited in a pretest array and three test arrays (see Figure 1). A 14-inch color display monitor presented the arrays to each participant. The pretest array, based on Matlin's (1983) facial characteristics, familiarized participants with the task. Test arrays contained three categories, each consisting of two contrasts, creating eight exemplars. The three test arrays were (a) a perceptual features array containing exemplars of geometric figures, categorized by size, shape and color; (b) a mixed properties 
array containing exemplars of vehicles contrasted by an equivalent amount of the combined perceptual features and conceptual attributes of color, era, and conjunctively size and type; (c) a conceptual attributes array containing exemplars of animals, with implicit contrasts of habitat, natural/biological classification, and maturity, but without useful contrasts on the basis of color or size (see Jackson \& Jelinek, 1993; Treisman \& Gelade, 1980 for information on real world problem solving approximated by tasks that include combinations of features). Each test array presented a $3 \times 3$ configuration with eight exemplars assigned randomly to nine cells, with one cell per array left empty.
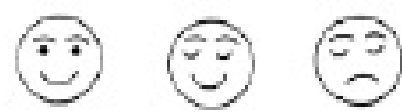

Frelet.Array
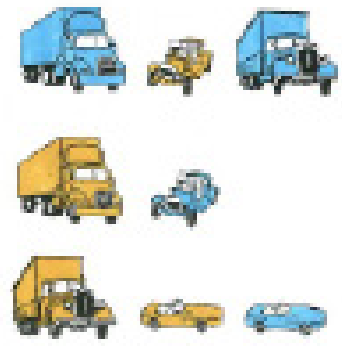

Mired Artay

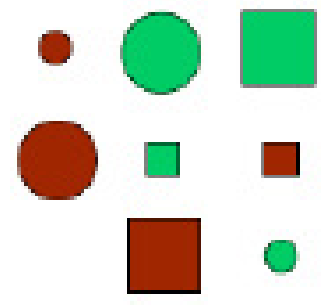

PerceptualArray

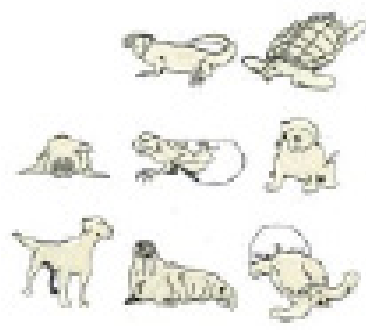

Coocepteal Array

Figure 1. Arrays displayed to participants. The pretest array appeared first to familiarize participants with the task, after which the test arrays (i.e., perceptual, mixed, conceptual) were presented. Order of presentation of the perceptual array, the mixed array, and the conceptual array was counterbalanced.

Instructions. Instructions resembled those used by Mosher \& Hornsby (1966): upon arriving at the testing area, each participant received oral instructions to ask questions to which the experimenter could answer "yes" or "no" in order to discover the designated target (correct picture) within each array in as few questions as possible ${ }^{4}$. The target sought by each participant in each

4 Instructions to participants included the qualification that the experimenter could not answer questions about the location of a particular picture, thereby preventing participants from asking about the row, column, or specific cell in which the target might lie. This ruled out a trivial problem solving strategy that is possible in such arrays, so the task better approximated real-world problem solving. A transcript of the instructions is available upon request. 
array varied randomly. A sound-insulated room with space for the equipment, the participant, and the experimenter served as the testing area. All participants viewed the pretest array after receiving the experimenter's instructions and, if necessary, additional clarification about the nature of the task. The pretest allowed procedural misunderstandings to be addressed before presentation of the test arrays. Participants viewed the test arrays serially, with order of presentation counterbalanced within each group. Each participant sat before the display monitor with a clear view of the screen throughout testing. The experimenter sat across from the participant but behind the monitor to avoid possible visual cueing. A brief tone accompanied the onset of each array and a camcorder with a remote condenser microphone recorded the participants' responses.

Scoring. Two observers coded each participant's questions by type into perceptual category questions, conceptual category questions, or syncretic questions. Perceptual category questions identified a contrast within the categories of color, shape, or size (e.g. "Is it blue?"). Conceptual category questions evoked background knowledge of an attribute, despite visual similarities, from which a relationship among exemplars was inferred (e.g. "Is it used to haul freight?"). Syncretic questions designated contrasts from combined categories, (e.g. "Is it a green circle?") or a specific exemplar (e.g. "Is it the new yellow convertible?"). A conservative estimate of interobserver reliability (Kappa $=.78$ ) indicated the strength of the agreement between the independent observers who classified the participants' questions. The observers resolved any disagreements concerning coding of the questions before statistical analysis. Table 1 shows the frequencies of the different question types by age group and array.

Response latency and processing time. Response latency was defined as the amount of time from presentation onset to the participant's initial question, or the end of experimenter's response (i.e. feedback) to a participant's subsequent question, using time elapsed to the first word of the question. Response latencies were determined from the video recording using the onscreen stopwatch function of a Panasonic WJ-810 time date generator, and were obtained for questions without falsestarts, interveningsentences, orextensivetalk. Obtainedresponselatencieswere used to calculate processing times corresponding to the syncretic, perceptual category, and conceptual category questioning strategies. Each participant's mean response latency forquestions coded as syncretic provided that individual's syncretic processing time. Likewise, his/her mean response latencies for questions coded as perceptual category and conceptual category represented the individual's perceptual and conceptual processing times respectively. Thus, processing time constituted an aggregate measure derived from questions across arrays. This measure also served to normalize the data by attenuating the skew common in raw response latencies. Processing times were calculated to the tenth of a second.

Post-test sorting task. To assess the validity of the conceptual attributes array in which participants needed to recognize particular conceptual contrasts in order to solve the problem, they performed a post-test sorting task. The task 
Table 1. Frequencies of Question Types Generated for Test Arrays by Different Age Groups

\begin{tabular}{cccccc}
\hline \multirow{2}{*}{ Question Type } & & \multicolumn{3}{c}{ Array } & \\
\cline { 3 - 5 } Syncretic & Ege Group & Perceptual & Mixed & Conceptual & Total \\
\hline & Middle Adolescent & 56 & 71 & 62 & 189 \\
& Young Adult & 50 & 70 & 44 & 164 \\
Perceptual Category & Early Adolescent & 158 & 67 & 4 & 229 \\
& Middle Adolescent & 155 & 72 & 6 & 233 \\
& Young Adult & 145 & 66 & 0 & 211 \\
Conceptual Category & Early Adolescent & 10 & 98 & 218 & 326 \\
& Middle Adolescent & 6 & 98 & 215 & 319 \\
& Young Adult & 6 & 94 & 198 & 298 \\
\hline
\end{tabular}

Note: The listed frequencies reflect the resolution of any coding disagreements by two independent observers. Because gender was not statistically significant in the processing time analysis, the frequency data were collapsed across gender.

required each participant to examine photocopies of the exemplars comprising the array individually mounted on $6 \mathrm{~mm} \times 6 \mathrm{~mm} \times 2 \mathrm{~mm}$ wooden blocks, placed in an unordered grouping on a table. With the adult lizard, the adult turtle,the infant walrus, the hatchling lizard, the puppy, the adult dog, the adult walrus, and the hatchling turtle grouped before them, participants received instructions to sort in three ways. After each sort the blocks were mixed together again. The experimenter instructed each participant to (a) place the infants and the adults in separate piles; (b) place the reptiles and the mammals in separate piles; and (c) place the water animals and the land animals in separate piles. The experimenter recorded the sorting errors for $\mathrm{a}, \mathrm{b}$, and $\mathrm{c}$ on a data sheet. An accuracy ratio was calculated for each participant.

\section{Results}

\section{Post-test sorting accuracy}

Sorting accuracy averages were calculated by gender and age group to determine whether confusion about the relevant attributes in the conceptual attributes array could have influenced participants' performance. Mean sorting accuracy for males andfemalesineachagegroupshowed thatnogroupwaslessthan $94 \%$ accurateonany conceptual contrast, thus supporting ourassumptions about participants' familiarity with the conceptual categories represented by the exemplars used in the test array. 


\section{Processing time of question types}

Because gender and age group comprised between-participant factors and question type a within-participant factor, the resulting nesting of variables called for multi-level modeling of the processing time data. The data were deemed to meet the assumptions of the procedure. Analyses detected no significant main or interaction effects for gender, but found significant main effects for age, $F(2,280)=3.05, p<.05$, and question type $F(2,280)=39.19, p<.0001$. Further, the procedure found an age group by question type interaction, $F(4,280)=3.15$, $p<.02$. Figure 2 shows the processing time means for the three age groups.

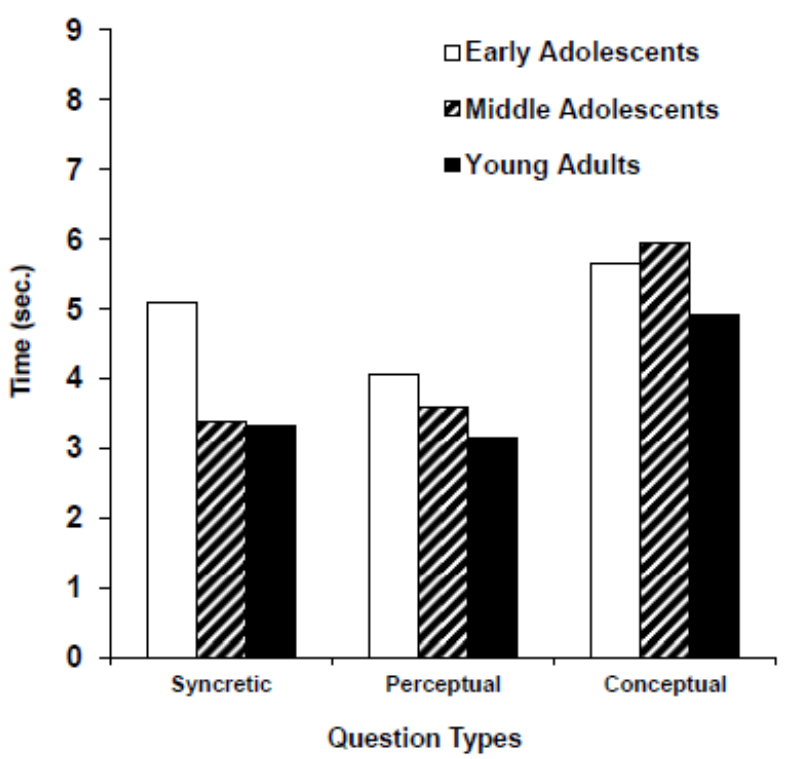

Figure 2.Mean processing times of question types by age groups.

A Least Squares Means procedure for preplanned comparisons analyzed processing time means by age and question type. For the two older age groups, conceptual category questions took significantly longer to generate than either perceptual category questions (middle adolescents: $\bar{X}_{\text {conceptual }}=5.95$, $\bar{X}_{\text {perceptual }}=3.58, p<.0001$; young adults: $\bar{X}_{\text {conceptual }}=4.91, \bar{X}_{\text {perceptual }}=3.14, p<.0001$ ) or syncretic questions (middle adolescents: $\bar{X}_{\text {syncretic }}=3.40, p<.0001$; young adults: $\left.\bar{X}_{\text {syncretic }}=3.34, p<.0005\right)$. In the youngest age group, both conceptual category questions $(\bar{X}=5.66, p<.0001)$ and syncretic questions $(\bar{X}=5.08$, $p<.05)$ took significantly longer to produce than perceptual category questions $(\bar{X}=4.07)$. No significant difference between the processing times of conceptual and syncretic questions $(p=.21)$ for the early adolescents was found. 


\section{Discussion}

\section{Summary and Connections to Other Research}

Aspects of the present study distinguish it from previous developmental studies of processing time. Kail (1991) summarized the results of several lines of research in which response times measured in milliseconds were common. The questions asked in the present study simply took more time. Perhaps the mental steps needed to verbalize a question created cognitive loads requiring more information processing time than, for example, name retrieval or mental addition. Just such an explanation was discussed by Bruner, Olver, and Greenfield (1966) and Eimas (1970).

Although the present study produced processing times of greater magnitude than those described by Kail $(1991,1993)$, they nonetheless follow the same developmental pattern of faster processing time with increasing age. On average, young adults asked any type of question more quickly than adolescents. Note that this experiment posed problems requiring verbal responses from participants with equivalent, if not the same accelerating information processing that supports age-related increases in working memory and fluid intelligence (Fry \& Hale, 1996; Kail \& Salthouse, 1994), as well as articulation speed (Kail, 1992; Kail \& Park, 1992).

Other published results indicate that adults are not only quicker than younger age groups, but more efficient in their use of questions to reduce the range of alternatives in arriving at the solution. Drumm and Jackson (1996), using the same arrays described in this report, measured questioning efficiency via alternative reduction scores, a measure developed by Siegler (1977). If a questioner draws appropriate categorical contrasts, the solution for each array is possible with three questions (of course, participants could do better or worse by making either lucky or unlucky guesses). Young adults significantly outperformed the two younger age groups on the efficiency of their third questions although, on the first question, average alternative reduction efficiency was equivalent across groups. Although this report focuses on processing times, Table 2 presents the efficiency means of questions asked by the groups in this study.

\section{Temporal Differences Between Question Types Explained}

An average temporal gap of approximately a second and a half separated perceptual category questions from conceptual category questions in each age group. The significantly shorter processing times of perceptual category questions suggest that perception and categorization of surface features occur quickly and demand little cognitively.

Although the mental demands of processing surface rather than deeper similarities (Estes, 1993; Wattenmaker, Nakamura, \& Medin, 1988) explain processing time differences favoring a perceptual over a conceptual organizational 
Table 2. Efficiency Means of First Three Questions for Test Arrays by Different Age Groups

\begin{tabular}{ccccccc}
\hline \multirow{2}{*}{ Question Type } & Age Group & Perceptual & Mixed & Conceptual & $\begin{array}{c}\text { Across } \\
\text { Arrays }\end{array}$ \\
\cline { 3 - 5 } & Early Adolescent & 0.481 & 0.471 & 0.364 & 0.439 \\
\cline { 3 - 5 } First Question & Middle Adolescent & 0.485 & 0.485 & 0.412 & 0.460 \\
& Young Adult & 0.487 & 0.460 & 0.423 & 0.457 \\
& Early Adolescent & 0.473 & 0.444 & 0.403 & 0.440 \\
& Middle Adolescent & 0.453 & 0.377 & 0.364 & 0.398 \\
& Young Adult & 0.428 & 0.442 & 0.418 & 0.430 \\
& Early Adolescent & 0.452 & 0.383 & 0.363 & 0.401 \\
& Middle Adolescent & 0.422 & 0.388 & 0.331 & 0.382 \\
& Young Adult & 0.476 & 0.425 & 0.384 & 0.433 \\
\hline
\end{tabular}

strategy, an unanticipated result requires further explanation. The youngest group needed nearly as much time to produce syncretic questions as conceptual category questions, in contrast with the two older groups. That is, early adolescents responded slowly in generating both syncretic and conceptual category questions. A developmental disparity apparently exists between two interrelated components of self-directed information seeking: categorizing, on the one hand, and constraining alternative solutions, on the other. Constraining alternatives via questions requires not only an ability to organize information categorically, but also requires hypothesis-testing, induction, and deduction to reach conclusions (Neimark \& Lewis, 1967; Siegler \& Liebert, 1975). By late childhood, most children organize world knowledge into categories (Markman, 1989), but still lack sufficient experience to empirically test hypotheses based on categorical thinking (Vygotsky, 1984/1936). At the onset of adolescence, accumulating experience promotes the use of focused hypothesis testing (Eimas, 1969; Gholson, 1980; Tumblin \& Gholson, 1981), although even then it is not always displayed (Kemler, 1978; Jackson \& Jelinek, 1993).

Syncretic questions differ from category questions by attempting to identify targets in a way that inefficiently distinguishes categories. Often such questions specify a single exemplar. Participants who used syncretic questions occasionally arrivedatacorrectalternativewithlessthanthreequestions. However, by eliminating only one option in the array (the exemplar mentioned) rather than focusing on a category contrast that reduces alternatives by half, syncretic questions more 
likely delay a solution. Eimas (1970) described the development of focusing as a gradual transition from guessing (a typical problem solving strategy among young children) to ordering information that ineffectively partitions stimuli (as in syncretic thinking), to consistent reliance on discriminative categories.

Compared to the older age groups, early adolescents seemed to expend more cognitive effort processing the multidimensional stimuli in the arrays. Why? Perhaps the demands of inferring relationships and attempting hypothesis tests using categorical knowledge produced the longer times that we observed. To elaborate, the longer processing times for conceptual category questions produced by all age groups reflect the cognitive demands of partitioning conceptual categories, whereas longer processing times for syncretic questions produced by early adolescents reflect the cognitive strain of hypothesis testing without adequately differentiated categories. The inefficient, time consuming strategies of early adolescence disappear by middle adolescence as hypothesis testing experience accrues with age.

\section{Theoretical Mechanisms Supporting Questioning}

For Vygotsky (1934/1986), speech, whether overt or inner, is the "instrument of thought" manifested in questions. Vygotsky further distinguished questions of decision as particularly important:

For example: What is it? Where did it come from? Who was that? When?

Why? Why was this done? Such a question cannot be answered with a simple "yes" or "no." On the other hand, questions of decision can be answered "yes" or "no," since the potential for decision is contained in the question itself. For example: Is this a rare plant? Was this rug brought from Persia? Such a question, especially if posed to oneself, is identical to the expression of a state of conscious expectation from which a hypothetical conclusion can be reached in some cases. (Vygotsky, 2002, p. 434)

The conditions of our experiment required participants to ask such questions of decision. Their category questions presumably followed the information seeking strategy of focusing (Bruner, Goodnow, \& Austin, 1956). Effectively using such self-directed information searches requires the following steps: (1) scanning an array, (2) identifying similarities among exemplars (i.e. categorization), (3) remembering feedback for questions already asked, (4) deciding which category to test (i.e. constrain), then (5) verbalizing a question. Proceeding through these steps takes time.

Age-related decreases in processing time for conceptual and syncretic questions also conform to Vygotsky's proposal that, with age and experience, inner speech increasingly integrates thought with language. Vygotsky believed experience provided the mechanism through which thought and language evolve from independent systems to systems that interact and integrate. In the present study, the process of organizing information to generate syncretic and conceptual questions apparently shortened with increasing age because the thought processes 
involved in seeking and testinghypothesesincreasinglyintegrated with the language processes of questioning. Presumably, verbalized hypothesis tests based purely on perceptual discriminations were sufficiently established across age groups and did not create much cognitive strain.

Other evidence establishes a link between language use and problem solving. For example, among children with diverse ability levels who tackled a variety of problems, thinking aloud provided clear benefits (Short, Evans, Friebert, \& Schatschneider, 1991; Short, et al., 1991). Pierce (1990) found that preschoolers who ask many questions remember more information from the answers they receive. Taken together, these findings suggest that language processes are tied to problem solving.

The reasons syncretic questions do not disappear altogether may be that such thinking requires less mental effort, at least for older individuals, and occasionally is effective. Early on, the intuitive hypothesis testing expressed by some syncretic questions overtakes wild, random guessing because of self-evident disadvantages in the latter approach ${ }^{5}$. But it still survives into adulthood because mature inquiry is so labor-intensive. Problem solvers can afford the cognitive demands of mature inquiry only when they process information quickly and possess the memory capacity for reflective thinking (Fry \& Hale, 1996). However, in situations of real-life uncertainty the pressure to reach a decision may be high, and the time to consider the alternatives correspondingly short.

\section{Overview, Limitations, and Implications}

The processing time of questioning has not been studied extensively. To fill this gap, this experiment presented to problem solvers of different ages multidimensional arrays incorporating perceptual and conceptual information. However, in order to derive a single processing time score for each person for each question type, it was necessary to include response latencies for questions from all arrays, making it impossible to determine any specific effects arising from the pattern of information in any individual array. Neither was it possible to determine whether a particular array contributed to systematic temporal differences among the types of questions generated early or later in a series.

Although our randomization procedures should have rendered individual differences equivalent across groups, those same procedures may have masked important patterns. Degree of impulsivity is one example of a factor that could influence both response latency and problem solving efficiency. Expertise, particularly with a particular conceptual domain, might shorten response times for questions too. For these reasons, the present study constitutes at besta starting point.

At a more general level, the present study was unable to determine whether processing times comprised serial processes, parallel processes or both, although

5 Questions coded as syncretic could combine two categorical contrasts in a single question (e.g. "Is it a blue car?") or they could specify a single exemplar (e.g. "Is it the old blue car?"). The former were usually more efficient than the latter. 
such distinctions may be important for a full understanding of response time effects (Luce, 1986). Replication and extension of this experiment is clearly needed. Also, despite Vygotsky's (1934/1986) noble attempt, the precise relationship between thought and language remains elusive (Fodor, 1972), and some conceptual categories lack clear membership criteria (Wittgenstein, 1953/1958). Nevertheless, the findings presented here conform to a pattern that is robust in the cognitive development literature.

What do studies such as this tell us about people solving real life problems using verbal processing? What do they ask themselves, and how might that help guide their thinking? If the findings reported here possess ecological validity, then the "adults only" recruitment practice of the Observer Corps possesses empirical support, and clearly the success of those sky watchers during World War II substantiates their questioning prowess. The speed with which identification problems are efficiently solved depends a great deal on the different processing demands of two strategies: one that recognizes and classifies surface features, and another that invokes background knowledge to establish implicit conceptual relationships. Both use the self-guiding process of inner speech to test hypotheses based on categorical organization. Perceptual category questions involve mere recognition, surface processing of available information, less computational effort, and correspondingly less processing time. Thus people generate perceptual category questions more quickly than conceptual category questions, which organize information based on inferred relationships. Syncretic questions risk much in inquiry, but they are produced quickly by adulthood and the immediacy of some real life situations does not allow time for thoughtful inquiry, forcing problem solvers to make their best guesses. The puzzle of how to promote both speedy and efficient questions of decision awaits future research.

\section{References}

Alexander, J. M., Johnson, K. E., Leibham, M. E., \& DeBauge, C. (2004). Constructing domain-specific knowledge in kindergarten: Relations among knowledge, intelligence, and strategic performance. Learning and Individual Differences, 15, 35-52. doi:10.1016/j.lindif.2004.07.001

Alexander, T. M., \& Enns, J. T., (1988). Age changes in the boundaries of fuzzy categories. Child Development, 59, 1372-1386.

Bruner, J. S., Goodnow, J., \& Austin, G. A. (1956). A study of thinking. New York: Wiley.

Bruner, J. S., Olver, R. R., \& Greenfield, P. M. (1966). Studies in cognitive growth. New York, NY: Wiley.

Clément, E. \& Gavornikova-Baligand, Z. (2010). Problem solving strategies by mentally retarded adults: Evidence from the twenty questions task. Psychologie Française, 55, 25-39.

Courage, M. L. (1989). Children's inquiry strategies in referential communication 
and in the game of twenty questions. Child Development, 60, 877-886. doi:10.1111/1467-8624.ep9676156

Deary, I. J. \& Der, G. (2005). Reaction time explains IQ's association with death. Psychological Science, 16, 64-69. doi:10.1111/j.0956-7976.2005.00781.x

Denney, N. W., Jones, F. W., \& Krigel, S. H. (1979). Modifying the questioning strategies of young children and elderly adults with strategy-modeling techniques. Human Development, 22, 23-36.

Drumm, P., \& Jackson, D. W. (1996). Developmental changes in questioning strategies during adolescence. Journal of Adolescent Research, 11, 283-303.

Edwards, J. C. (1969). Effect of instruction and concomitant variables on multiple-categorization ability. Journal of Educational Psychology, 60, 138143. doi: $10.1037 / \mathrm{h} 0027013$

Eimas, P. D. (1969). A developmental study of hypothesis behavior and focusing. Journal of Experimental Child Psychology, 8, 160-172. doi:10.1016/00220965(69)90037-X

Eimas, P. D. (1970). Information processing in problem solving as a function of developmental level and stimulus saliency. Developmental Psychology, 2(2), 224-229. doi:10.1037/h0028746

Estes, W. K. (1993). Concepts, Categories, and Psychological Science. Psychological Science, 4(3), 143-153.

Fodor, J. (1972). Some reflections on L. S. Vygotsky's Thought and Language. Cognition, 1(1), 83-95. doi:10.1016/0010-0277(72)90046-7

Fry, A. F. \& Hale, S. (1996). Processing speed, working memory, and fluid intelligence. Psychological Science, 7(4), 237-241.

Gholson, B. (1980). The cognitive-developmental basis of human learning: Studies in hypothesis testing. New York, NY: Academic Press.

Gibson, J. J. (1947). Motion picture testing and research. Armed Forces Aviation Psychology Program Research Reports, Report No. 7. Washington, DC: U.S. Government Printing Office.

Hale, S. (1990). A global developmental trend in cognitive processing speed. Child Development, 61, 653-663.

Hale, S., \& Jansen, J. (1994). Global processing time coefficients characterize individual and group differences in cognitive speed. Psychological Science, $5,384-388$.

Hambrick, D. Z., \& Engle, R. W. (2002). Effects of domain knowledge, working memory capacity, and age on cognitive performance: An investigation of the knowledge-is-power hypothesis. Cognitive Psychology, 44, 339-388.

Hayes, B. K., \& Taplin, J. E. (1993). Developmental differences in the use of prototype and exemplar-specific information. Journal of Experimental Child Psychology, 55, 329-352. doi:10.1006/jecp.1993.1019

Jackson D. W., \& Jelinek, M. (1993). Differential use of constraining questions by gender and matrix. Perceptual and Motor Skills, 76, 887-895.

Kail, R. (1991). Development of processing speed in childhood and adolescence. 
Advances in Child Development and Behavior, 23, 151-185. doi:10.1016/ S0065-2407(08)60025-7

Kail, R. (1992). Processing speed, speech rate, and memory. Developmental Psychology, 28, 899-904.

Kail, R. (1993). Processing time decreases globally at an exponential rate during childhood and adolescence. Journal of Experimental Child Psychology, 56, 254-265. doi:10.1006/jecp.1993.1034

Kail, R. (1996). Nature and consequences of developmental change in speed of processing. Swiss Journal of Psychology, 55, 133-138.

Kail, R., \& Park, Y. (1994). Processing time, articulation time, and memory span. Journal of Experimental Child Psychology, 57, 281-291. doi:10.1006/ jecp.1994.1013

Kail, R., \& Salthouse, T. A. (1994). Processing speed as a mental capacity. Acta Psychologica, 86, 199-225. doi: 10.1016/0001-6918(94)90003-5.

Keil, F. C. (1989). Concepts, kinds, and cognitive development. Cambridge, MA: MIT Press.

Keil, F. C., \& Kelly, M. H. (1987). Developmental changes in category structure. In S. Harnad (Ed.), Categorical perception (pp. 491-510). New York, NY: Cambridge University Press.

Kemler, D. G. (1978). Patterns of hypothesis testing in children's discriminative learning: A study of the development of problem-solving strategies. Developmental Psychology, 14, 653-673. doi:10.1037/0012-1649.14.6.653

Luce, R. D. (1986). Response times: Their role in inferring elementary mental organization. New York, NY: Oxford University Press.

Luria, A. R. (1976). Cognitive development: Its cultural and social foundations (M. Lopez-Morillas, \& L. Solotaroff, Trans.). Cambridge, MA: Harvard University Press. (Original work published 1974)

Mandler, J. M., \& Robinson, C. A. (1978). Developmental changes in picture recognition. Journal of Experimental Child Psychology, 26, 122-136. doi:10.1016/0022-0965(78)90114-5

Markman, E. M. (1989). Categorization and naming in children: Problems of induction. Cambridge, MA: MIT Press.

Matlin, M. (1983). Cognition. New York, NY: Holt, Rinehart \& Winston.

Marschark, M., \& Everhart, V. S. (1999). Problem-solving by deaf and hearing students: Twenty questions. Deafness Education International, 1, 65-82.

Marshall, R. C., Karow, C. M., Morelli, C. A., Iden, K. K., \& Dixon, J. (2003). Problem-solving by traumatically brain injured and neurologically intact subjects on an adaptation of the twenty questions test. Brain Injury, 17, 589608.

Mervis, C. B. \& Rosch, E. (1981). Categorization of natural objects. In M. R. Rosenzweig \& L.W. Porter (Eds.), Annual Review of Psychology: Vol. 32 (pp. 89-115). Palo Alto, CA: Annual Reviews.

Mosher, F. A., \& Hornsby, J. R. (1966). On asking questions. In J. S. Bruner, R. 
R. Olver \& P.M. Greenfield, et al., Studies in cognitive growth (pp. 86-102). New York, NY: Wiley.

Neimark, E. D., \& Lewis, N. (1967). The development of logical problem solving strategies. Child Development, 38, 107-117.

Nelson, K. E., \& Earl, N. (1973). Information search by preschool children: Induced use of categories and category hierarchies. Child Development, 44, $682-685$.

Pierce, J. W. (1990). The more they ask, the more they remember: Variables related to preschoolers' memory for answers to their own questions. Child Study Journal, 20, 279-286.

Short, E. J., Evans, S. W., Friebert, S. E., \& Schatsschneider, C. W., (1991). Thinking aloud during problem solving: Facilitation effects. Learning and Individual Differences, 3, 109-122. doi: 10.1016/1041-6080(91)90011-O

Short, E. J., Schatschneider, C., Cuddy, C. L., Evans, S. W., Dellick, D. M., \& Basili, L. A., (1991). The effect of thinking aloud on the problem-solving performance of bright, average, learning disabled, and developmentally handicapped students. Contemporary Educational Psychology, 16, 139-153. doi:10.1016/0361-476X(91)90033-H

Siegler, R. S. (1977). The twenty questions game as a form of problem solving. Child Development, 481, 395-403.

Siegler, R. S., \& Liebert, R. M. (1975). Acquisition of formal scientific reasoning by 10 and 13 year olds; designing a factorial experiment. Developmental Psychology, 11, 401-402.

Slowiaczek, L. M., Klayman, J., Sherman, S. J., \& Skov, R. B., 1992. Information selection and use in hypothesis testing: What is a good question and what is a good answer? Memory and Cognition, 20, 392-405.

Sperber, R. D., Davies, D., Merrill, E. C., \& McCauley, C. (1982). Cross-category differences in the processing of subordinate-superordinate relationships. Child Development, 53, 1249-1253.

Sternberg, R. J. (1982). Natural, unnatural, and supernatural concepts. Cognitive Psychology, 14, 451-488. doi:10.1016/0010-0285(82)90016-0

Treisman, A., \& Gelade, G. (1980). A feature integration theory of attention. Cognitive Psychology, 12, 97-136. doi:10.1016/0010-0285(80)90005-5

Tumblin, A., \& Gholson, B. (1981). Hypothesis theory and the development of conceptual learning. Psychological Bulletin, 90, 102-124. doi:10.1037/00332909.90.1.102

Upton, D. \& Thompson, P. J. (1999). Twenty questions task and frontal lobe dysfunction. Archives of Clinical Neuropsychology, 14, 203-216. doi:10.1016/S0887-6177(98)00013-4

Victory, A. C. (1968). A brief history of aircraft dentification training. Alexandria, VA: George Washington University Human Resources Research Office.

Vygotsky, L. S. (1986). Thought and language. Cambridge, MA: MIT Press. (Original work published 1934) 
Vygotsky, L. S. (2002). The development of thinking and ormation of concepts in the adolescent. In R. W. Rieber \& D. K. Robinson (Eds.), The essential Vygotsky (pp. 415-470). New York, NY: Kluwer Academic/Plenum Publishers.

Wattenmaker, W. D., Nakamura, G. V., \& Medin, D. L. (1988). Relationships between similarity-based and explanation-based categorization. In D. Hilton (Ed.), Science and natural explanation: Commonsense conceptions of causality (pp. 204-240). London: Harvester Press.

Wittgenstein, L. (1958). Philosophical investigations. Oxford: Basil Blackwell. (Original work published 1953) 